\title{
Article \\ Mechanism of Rake Frame Shear Drainage during Gravity Dewatering of Ultrafine Unclassified Tailings for Paste Preparation
}

\author{
Xinming Chen ${ }^{1,2,3}$, Jiangling Zhang ${ }^{1,2,3}$, Huazhe Jiao ${ }^{1,2,3, *}$, Kaijian Hu ${ }^{4,5}$, Linhai Wan ${ }^{4,5}$, Zhuen Ruan 6 \\ and Liuhua Yang ${ }^{1,2,3, *}$
}

Citation: Chen, X.; Zhang, J.; Jiao, H.; Hu, K.; Wan, L.; Ruan, Z.; Yang, L. Mechanism of Rake Frame Shear Drainage during Gravity Dewatering of Ultrafine Unclassified Tailings for Paste Preparation. Minerals 2022, 12, 240. https://doi.org/10.3390/ $\min 12020240$

Academic Editor: Carlito Tabelin

Received: 6 January 2022

Accepted: 5 February 2022

Published: 13 February 2022

Publisher's Note: MDPI stays neutral with regard to jurisdictional claims in published maps and institutional affiliations.

Copyright: (C) 2022 by the authors. Licensee MDPI, Basel, Switzerland. This article is an open access article distributed under the terms and conditions of the Creative Commons Attribution (CC BY) license (https:/ / creativecommons.org/licenses/by/ $4.0 /)$.
1 School of Civil Engineering, Henan Polytechnic University, Jiaozuo 454003, China; chenxinming@163.com (X.C.); z17550176326@163.com (J.Z.)

2 Provincial Key Laboratory of Underground Engineering and Disaster Prevention and Control, School of Civil Engineering, Henan Polytechnic University, Jiaozuo 454003, China

3 State Collaborative Innovation Center of Coal Work Safety and Clean-Efficiency Utilization, School of Civil Engineering, Henan Polytechnic University, Jiaozuo 454003, China

4 Jiangxi Province Key Laboratory of Mining Engineering, Jiangxi University of Science and Technology, Ganzhou 341000, China; hukaijian@jxust.edu.cn (K.H.); wanlinhai@minmetals.com (L.W.)

5 Jiangxi Xiushui Xianglushan Tungsten Co., Ltd., Jiujiang 332400, China

6 School of Civil and Resources Engineering, University of Science and Technology Beijing, Beijing 100083, China; ustb_ruanzhuen@hotmail.com

* Correspondence: jiaohuazhe@126.com (H.J.); yanglh@hpu.edu.cn (L.Y.)

\begin{abstract}
To study the mechanism of reverse percolation and drainage of unclassified tailings, improve the disposal concentration of tailings and solve the bottleneck in the development of filling technology, this study performed semi-industrial flocculation and sedimentation tests using macroscopic continuous thickener tests and a self-developed continuous thickener test platform to observe the evolution pattern and formation mechanism of unclassified tailings flocs. Then, in situ sampling was performed on the compressed thickener zone of tailings at the bottom of the bed with the help of industrial CT scanning tests and 3D images. Avizo software was used to establish the seepage channels and construct an evolutionary model to analyze the effect of tailings dewatering and concentration on tailings concentration from a microscopic perspective. The study shows that the distribution of seepage channels is closely related to the height of the bed. As the bed height increases, the bed concentration increases; shear has a significant effect on the water flow inside the pore space. After shear, the water between the sample pores has been discharged. Therefore, the flow rate is relatively slow. Shear produces pressure and tension effects, breaking the static equilibrium between flocs and water forming seepage channels. Shear can effectively break the floc structure and release the water so that the mutual position between flocs and water constantly changes, The concentration of the tailings bed is increased.
\end{abstract}

Keywords: paste-filling; flocculation and sedimentation tests; three-dimensional reconstruction; shear action; dewatering and concentration mechanisms

\section{Introduction}

With the development of the economy and society, the demand for metal mineral resources is increasing, and resource extraction has become a pillar industry of the world economy [1-3]. However, as the productivity of society increases, large quantities of mineral resources are consumed, and the development of shallow surface resources is becoming increasingly difficult. There is no doubt that low-concentration discharge is an important factor in the occurrence of disasters in tailings ponds, and low-concentration disposal methods no longer sufficient to meet the current production needs of mines [4]. Therefore, it is necessary to alter previous thinking regarding tailings disposal and change 
the discharge method, ensure safe construction (whereby paste-filling technology can effectively save land resources), protect the ecological environment and reduce stratum collapse. Therefore, a high concentration of unclassified tailings slurry is a prerequisite for the preparation of high-quality paste. Green disposal technology of whole tailings requires the tailing to be made into paste-like material without stratification, segregation and precipitation for downhole filling and surface stockpiling, thus improving the safety of downhole operation and controlling surface collapse [5]. Paste thickener is the process of reversing the osmosis of water out of the paste by increasing the concentration of the tailings slurry and reducing the internal moisture of the paste [6,7].

The key issue in unclassified tailings paste-filling technology is paste dewatering. Scholars at home and abroad have conducted substantial research on paste thickening.

Jiao et al. analyzed the mechanical characteristics of the rake frame. They noted that increasing the mud layer height and underflow concentration is a useful development direction regarding the thickener [8]. By studying the thickening performance of unclassified tailings flocs and the size evolution law in the flocculation and settlement process and then examining the influence of different types of flocculant on the thickening performance of tailings, it was found that a too-large molecular weight of flocculant resulted in a slower settling speed and a smaller underflow concentration. By studying the effect of flocculation settling on the rheological properties of the tailings, it was also determined that the correct amount of flocculant is beneficial to the further compacting and dewatering of the slurry and the operation of the rake frame [9-11].

Researchers found that as the concentration in the compression zone increased, the particle cluster spacing decreased, and the flocs came into contact with one another, forming a beehive structure with a certain strength during the settling process [12,13]. Chu et al. proposed that preconcentration of tailings using an agitated reflux classifier could improve the properties of tailings particles and facilitate an increase in tailings concentration [14]. Wei, $\mathrm{W}$ et al. found that polypropylene macromolecules could effectively dewater and densify tailings and that macromolecular monomer copolymers reduced viscosity and shear sensitivity, but it is not possible to accurately describe the mechanism of underflow thickening of ultrafine whole tails [15].

Researchers have also found that shear during thickening affects the floc structure and have analyzed the percolation channels and fine percolation in the thickening zone; Other researchers have found that as the $\mathrm{pH}$ increases, the denser the floc structure becomes, the more favorable it is to the underflow concentration, but the denser floc structure creates greater resistance to the operation of the rake frame [16]. Scholars have also used vacuum filtration testing machines to test the filtration and dewatering performance of flotation tailings slurries with different particle size distributions, mass concentrations, and flocculant dosage to study the importance of accurately controlling the filling slurry concentration for good filling quality $[17,18]$.

At the same time, research on tailings paste-filling techniques has been gradually refined and developed. Numerous scholars agree that combined tailings paste-filling techniques are preferable.

Di et al. investigated how to optimize flocculant performance and apply shear to enhance the dewatering process and compared this approach with the needs of conventional flocculation processes at low material solid concentrations [19]; Sun et al. determined the feasibility of the combined paste-filling technique by conducting industrial field tests and performed industrial field tests [20].

Scholars analyzed the nature of the paste during pipeline transport through the Bingham rheological model and derived the rheological parameters of the slurry at different concentrations [21,22]. Other scholars found that coalmine paste-filled materials cause a reduction in porosity and a reduction in capillary pores during the hydration reaction [23-25]. Several scholars also found that dense dehydration is an important factor in determining the overall thickening performance. Metal ore tailings pose difficulties in 
dewatering unclassified tailings slurries because of their extremely fine particle size and slow settling rate [26-28].

D'Avino et al. suggested that flocculation can increase the effective particle size to improve the settling rate but may also increase interionic interference [29]. It has also been shown through relevant tailings physical experiments that naturally settled tailings do not form a dense fill and require flocculant addition to improve the denseness [30,31]. The optimum range of flocculant addition and sand feed was found by other scholars to achieve sand bin top overflow water clarification and ensure tailings fill utilization.

Most of the previously described experiments have investigated static patterns in the settling of flocs. There is a lack of research on the fine-scale settling patterns of flocs. Additionally, most of the experiments focus on the nature of the flocculant as the main variable. There is a lack of research on factors external to the slurry.

Therefore, we undertook the investigation of other factors that influence the flocculation and settlement of the tailings. Semi-industrial flocculation settling tests were conducted using macroscopic continuous concentration tests with the aid of a self-developed continuous concentration test rig to investigate the influence of the rake frame mixing speed on the settling of the tailings.

The evolution of the tailings flocs and the formation mechanism were observed to study the denseness effect of the bottom bed. In situ sampling of the tailings compaction zone at the bottom of the bed was performed, and industrial CT scanning tests and image processing were conducted to investigate the morphological characteristics of the pores at the height of the bed [32].

Finally, the processed images were reconstructed in three dimensions, and the pore structure was extracted to analyze the characteristics and evolution mechanism of the floc pore structure, to reveal the influence of the floc pore structure evolution on the density effect and drainage performance and to analyze the concentration change of the tailings flocs at the bottom of the bed under shear conditions. A mechanical analysis of the floc structure evolution was performed to determine the mechanism of floc pore structure evolution under shear and analyze the influence of seepage channels on floc thickener ability. A quantitative analysis of the evolution of pore structure morphology and position during dynamic compression was conducted. A model of seepage channel formation and evolution was established to analyze tailings dewatering and the concentration mechanism from a microscopic perspective.

\section{Materials and Methods}

\subsection{Materials}

The determination of the physical properties of tailings is the basis of flocculation and sedimentation tests [33,34]. However, different types of flocculant have different flocculation effects on the tailings. Therefore, selecting the appropriate flocculant and the optimum concentration ratio of the input material is a prerequisite for the dynamic thickener test.

The tailings used in the test was from a copper mine. It has a high mud content and is characterized by poor settling properties, high transport resistance and poor setting properties after adsorption of cement, which seriously affects tailings disposal and utilization. The physical properties of the unclassified tailings are shown in Table 1.

Table 1. Basic physical properties of unclassified tailings.

\begin{tabular}{ccccc}
\hline Specific Gravity & Loose Volume Weight & Compact Density & Loose Porosity & \multicolumn{2}{c}{ Compact Porosity } \\
\hline $\mathrm{t} / \mathrm{m}^{3}$ & $\mathrm{t} / \mathrm{m}^{3}$ & $\mathrm{t} / \mathrm{m}^{3}$ & $(\%)$ & $(\%)$ \\
\hline 3.01 & 1.44 & 1.62 & 55.31 & 45.58 \\
\hline
\end{tabular}

The particle size classification of the soil sample is termed the gradation and is generally determined by sieve tests. The particle size distribution of the tailings soil sample 
affects not only the dewatering effect of the dense tailings but also the strength of the filling body. If the tailings have a high content of ultrafine particles, the flocculation formation of the flocculation network structure will cause difficulties in dewatering. Therefore, to improve the underflow concentration, it is important to study the dense dewatering performance of such tailings with a high sediment content. The particle distribution size of the tailings is shown in Figure 1.

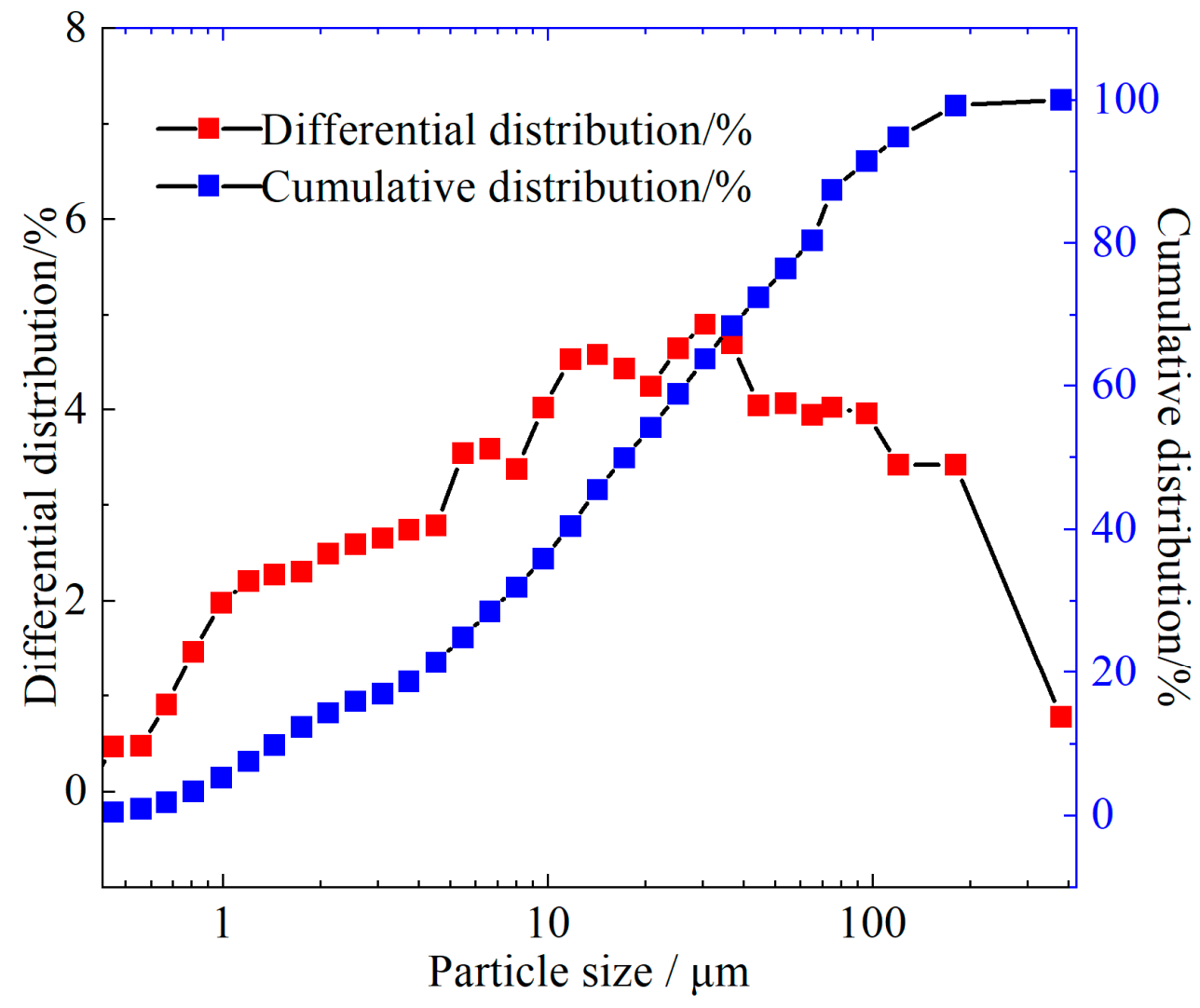

Figure 1. Particle size distribution of the unclassified tailings.

As shown in Figure 1, the median particle size D50 of all tailings is $17.20 \mu \mathrm{m}$; D10 is $1.56 \mu \mathrm{m}$; D90 is $94.34 \mu \mathrm{m} ;-200$ mesh particles $(74 \mu \mathrm{m})$ The content reaches $87.4 \%$ and -400 mesh $(37 \mu \mathrm{m}) 68.36 \%$. According to the geotechnical test, the particle size distribution of the tailings is good, because it belongs to "ultra-fine total tailings".

\subsection{Methods}

The tailings settling process is simulated by a self-developed small continuous thickening test platform, which includes the functions of continuous feeding, continuous discharging and adjustable rake frame speed. The platform can obtain key parameters, such as settling speed, settling concentration, stirring torque and its change law over time during the continuous thickening process. Assemble the experimental equipment, fix the top motor, install the welded rake frame to the bottom of the motor, and ensure that the climbing frame does not deflect in the settlement column and scratch the inner wall of the settlement column. Then, the full tail mortar and flocculant solution with the target concentration are configured in the material preparation barrel. In order to ensure that the tail mortar does not settle, a small mixer is used for continuous mixing, as follows: pump clean water into the settling column, start up and test run according to the actual process conditions, adjust the pumping speed, and achieve the target flow under actual conditions. The platform can simulate the real thickener operation and thus improve the rationality of the research results. The platform's structure is shown in Figure 2. 

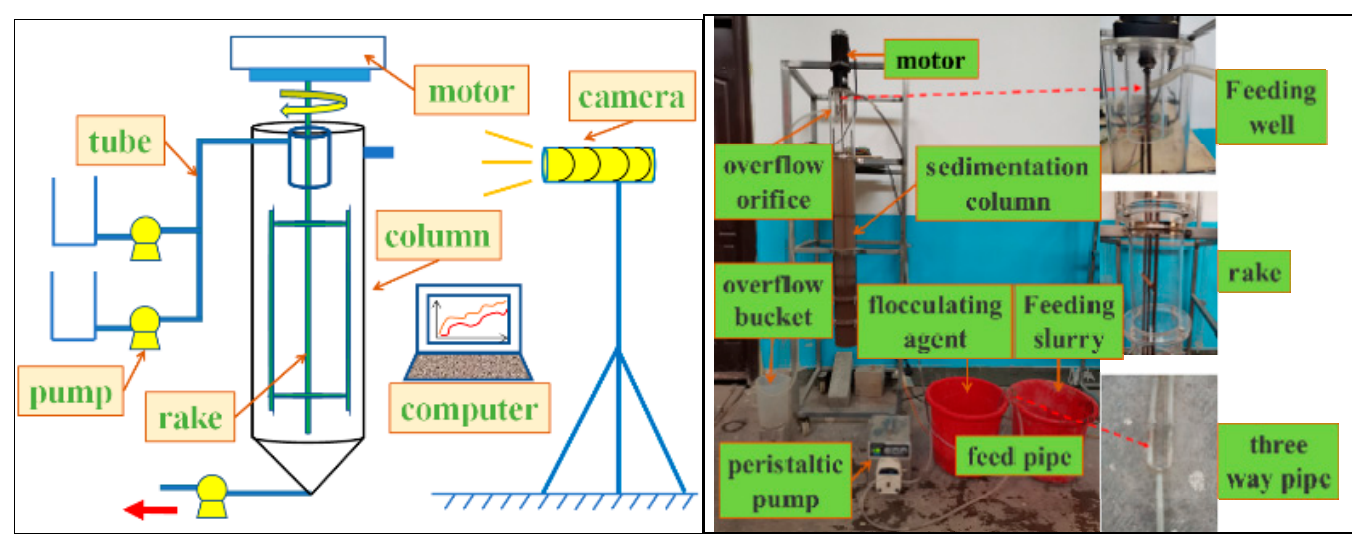

Figure 2. The overall layout of the experimental platform.

The basic parameters for the concentration test were determined according to the results of the indoor interval experiments, and the tests were performed using the orthogonal test method. Four factors were studied: solid flux, rake frame agitation speed, feed concentration and bed height, and three levels were set for each factor. A four-factor, three-level orthogonal test table L9 (34) was selected to arrange the orthogonal test $[35,36]$ (Table 2).

Table 2. Selection of test factors and levels.

\begin{tabular}{cccccc}
\hline \multicolumn{1}{c}{ Factor } & Unit & $\mathbf{1}$ & $\mathbf{2}$ & $\mathbf{3}$ \\
\cline { 1 - 3 } Level & & $\mathrm{th}^{-1} \mathrm{~m}^{-2}$ & 0.1 & 0.2 & 0.3 \\
Solid flux & $\mathrm{rpm}$ & 0 & 1 & 2 \\
Mixing speed & & 5 & 10 & 15 \\
Feeding concentration & $\mathrm{cm}$ & 10 & 20 & 301 \\
Bed height & & $\mathrm{cm}$ & & \\
\hline
\end{tabular}

The experimental scheme was planned to perform a multifactor influence study. Three levels of reference were set for each influencing factor. An orthogonal test with four factors and three levels was adopted. Finally, through theoretical analysis and sampling tests, a group of experiments with a strong influence on the underflow concentration was selected for analysis.

Sample preparation of solid-liquid mixtures is the key to microstructure scanning experiments. An undisturbed sample of the compressed phase was extracted using the in situ sampling-drying method for CT scanning. The experimental procedure is shown in Figure 3.

Shear conditions of $0 \mathrm{rpm}, 1 \mathrm{rpm}$ and $2 \mathrm{rpm}$ were added to study the settling pattern of the tailings flocs during flocculation and settlement and the evolution of the bottom flocs during dense compression. The size of the flocs under shear is small. However, the structure is denser because the floc structure undergoes a "flocculation-destruction-flocculation" process under the shearing action of the rake frame.

The raking frame breaks up the loose floc structure, the settling trajectory of the smaller floc structure in the settling column is changed, and the required settling time increases.

The flocs can be fully bridged during this process by the flocculation effect. The surrounding fine particles are continuously adsorbed on the flocs, the floc structure becomes denser, and the connectivity between the skeleton particles is better. The fine particles fall into the bottom bed, the floc structure is further compacted, and the shearing effect improves the density effect of the flocs. 

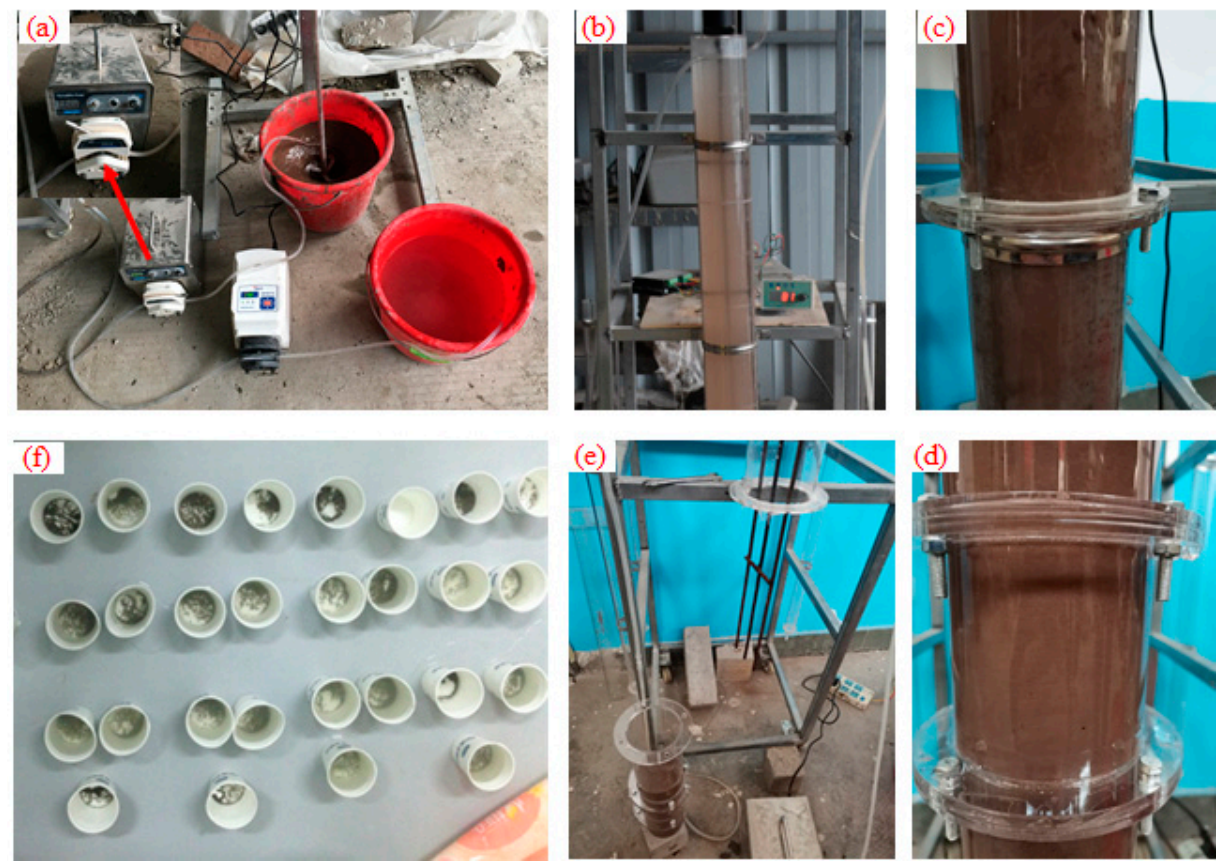

Figure 3. Experimental process of tailings flocculation concentration. (a) Tailing mortar mixing and parameter setting of a peristaltic pump. (b) Tailing mortar mixed with flocculant. (c) Flocculation settlement under shear conditions. (d) Flocculation settlement without shear. (e) Bottom bed floc density. (f) Bottom discharge concentration test.

After the flocculation and sedimentation experiments, by observing the floc structure at the bottom of the bed, it was found that the floc structure at $0 \mathrm{rpm}$ was looser, with more pores and a larger pore size (Figure $4 \mathrm{a}$ ). The floc structures at $1 \mathrm{rpm}$ and $2 \mathrm{rpm}$ were denser, with smaller pore sizes (Figure $4 \mathrm{~b}$ ). These findings indicate that shearing has a nonnegligible effect on the floc structure at the bottom of the bed and that shearing in the other direction improves the floc concentration at the bottom of the bed, increases the floc density there, and reduces the pore size distribution of the floc structure. To better observe the fine pore structure of the flocs, subsequent studies were conducted with the aid of CT scans.

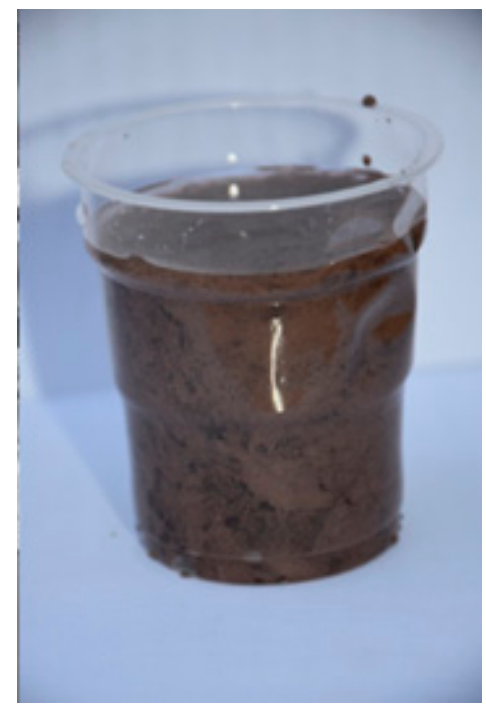

(a)

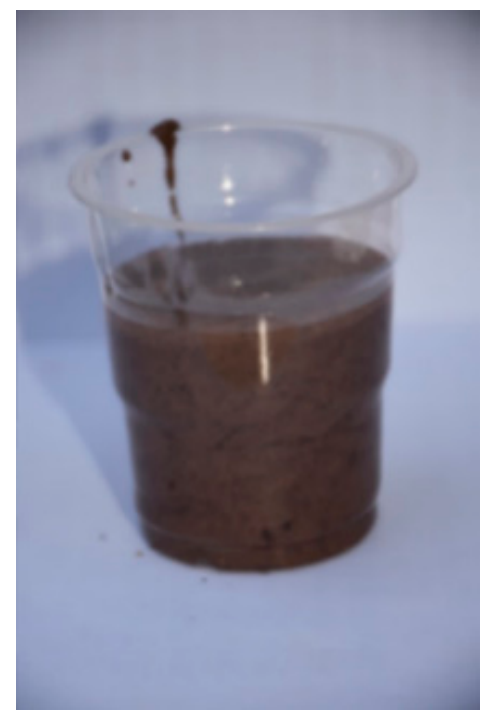

(b)

Figure 4. Bottom floc sampling. (a) Sampling without shear conditions; (b) Sampling under shear conditions. 
CT technology has undergone continuous development and is increasingly used in geotechnical engineering and other fields because of the advantages it offers, such as nondestructive testing $[37,38]$. The CT scanning device used for this test was a Phoenix $\mathrm{v} \mid$ tome $\mid \mathrm{x}$ high-precision industrial microscope CT scanning system (GE Inspection Technologies, Huerth, Germany). After repeated debugging of the scanning system parameters, the final magnification was determined to be $1000 \times$, and the resolution of the scanning unit was five $\mu \mathrm{m}$. Pores larger than $5 \mu \mathrm{m}$ (i.e., 1 pixel) could be detected, the interval between image layers was $5 \mu \mathrm{m}$, and the scanning length was approximately $100 \mathrm{~mm}$.

Industrial CT scans were performed with the same parameters and in the same orientation for both experiments. The final dimensions of the specimen were $150 \mathrm{~mm} \times 12 \mathrm{~mm}$ (height $\times$ diameter); the scanning process is shown in Figure 5. The scanning system is at a high level in terms of performance indicators compared to domestic and foreign systems. The experimental equipment can also provide a platform for microscopic studies of metallic and nonmetallic mining products.

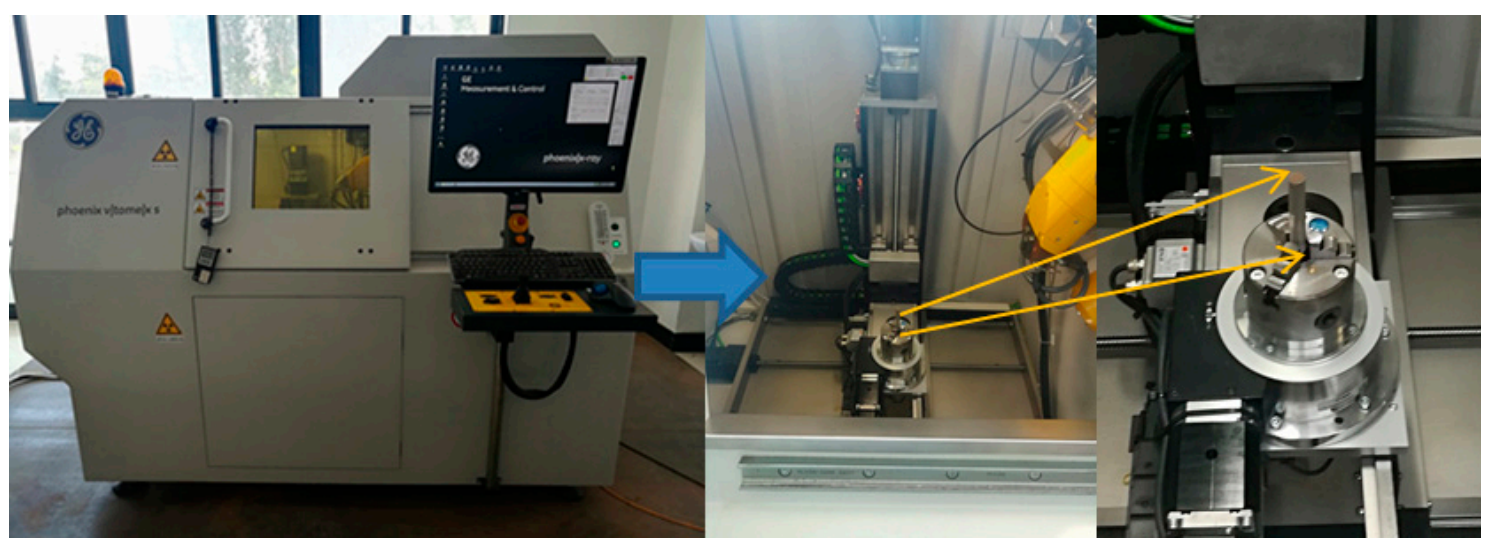

Figure 5. High-precision industrial CT scanning of compressed bed.

\section{Results}

3.1. Structural Characteristics and Evolution of Flocs in the Settling State of Tailings with/without Shear

The formation of percolation channels by floc morphology under compression is discussed. The compressed state of flocs and seepage channels at different heights within the bed are shown in Figure 6. The flocs are widely spaced in the upper part of the tailings bed, and the seepage channels are well developed and obvious. As the height of the bed increases, the particles become denser, the number of seepage channels decreases, the size decreases, and the bed concentration increases.

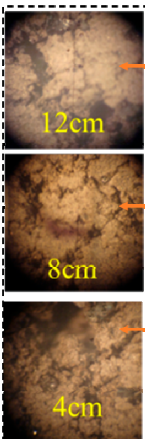

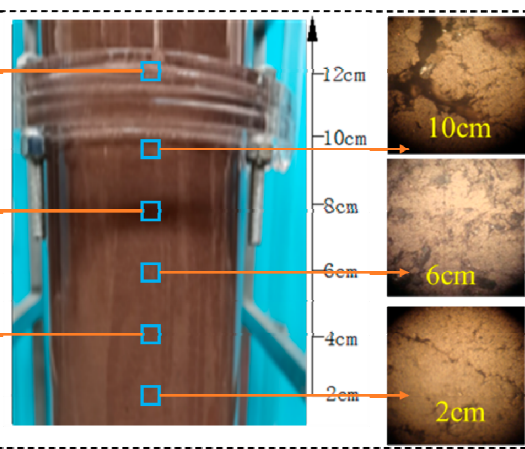

(a)
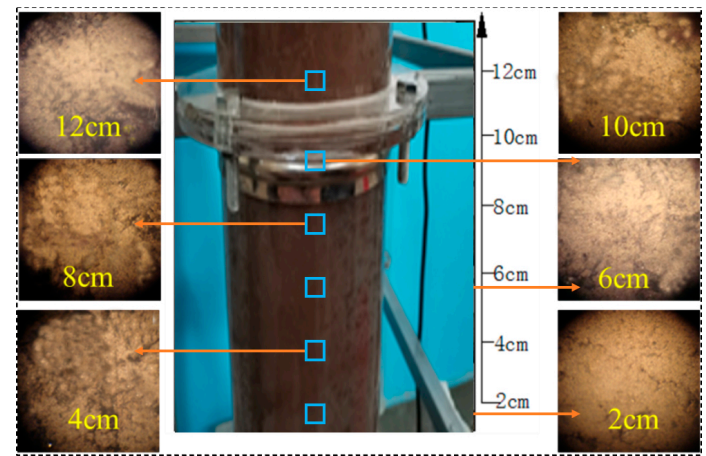

(b)

Figure 6. Tailings beds and image acquisition. (a) Distribution of the nonshear tailings bed. (b) Distribution of the shear tailings bed. 
To capture the floc morphology more clearly, the SEM scanning results shall be processed subsequently, the floc morphology shall be extracted, and the redundant display information shall be eliminated. It shall be processed through the steps of de-irritability, filtering and binarization with the help of graphics processing software.

The larger the value of the fractal dimension of the floc is, the denser the floc. The images in Figure 6 are processed, and the fractal dimension is calculated as shown in Figures 7 and 8. The tailings particles gradually show a state of aggregation under the action of stirring, showing a clear hierarchical distribution in the image and obvious floc net structure. With continuous shear and stirring, the flocs continue to gather and become denser. The fractal relationship between the mass $M$ of an object and its microscopic characteristic length $R$ is expressed as follows:

$$
M(R) \propto R^{D_{f}}
$$

where $D_{f}$ is the fractal dimension.

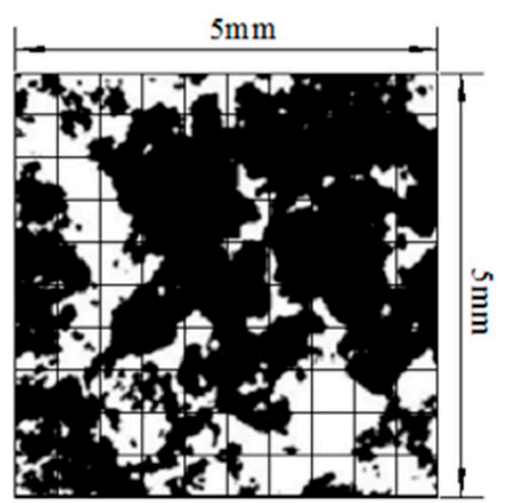

(1) $12 \mathrm{~cm}$

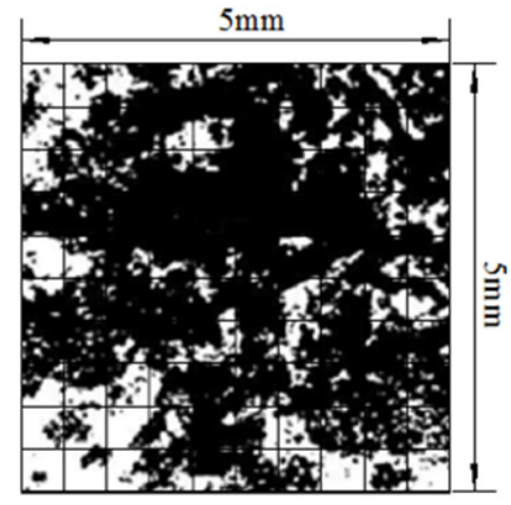

(4) $6 \mathrm{~cm}$

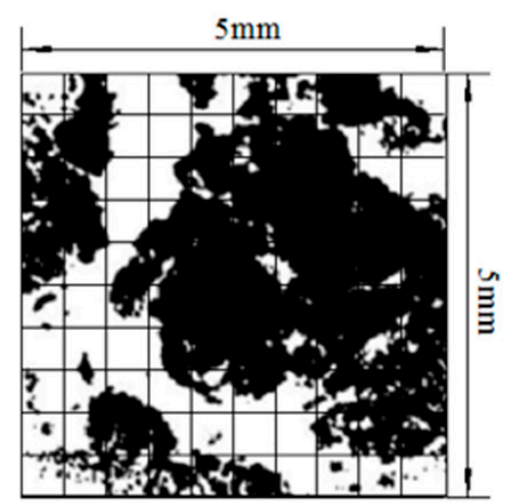

(2) $10 \mathrm{~cm}$

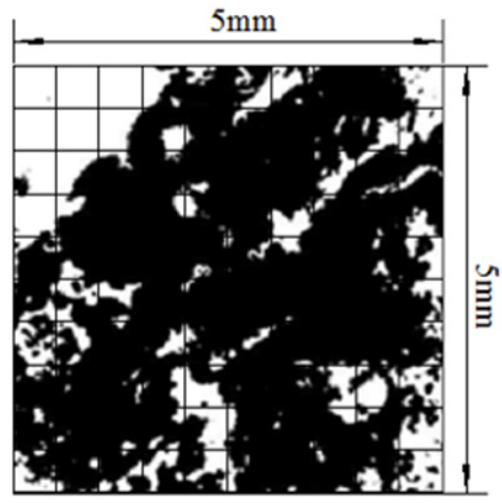

(5) $4 \mathrm{~cm}$

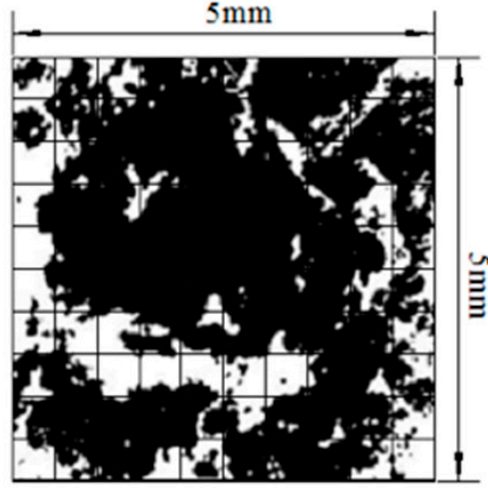

(3) $8 \mathrm{~cm}$

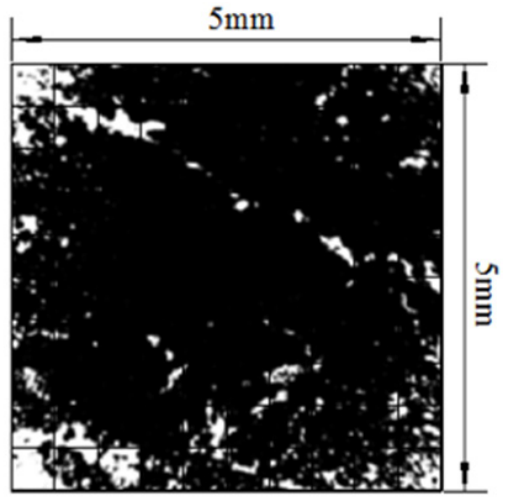

(6) $2 \mathrm{~cm}$

Figure 7. Binarization of bed seepage channel distribution images and box dimension calculation.

As shown in Figure 9, the fractal dimension values that characterize the size and connectivity of the seepage channels tend to decrease as the bed height decreases, with the fractal dimension values increasing at greater heights. The distribution of the non-shear tailings bed is as follows: the box dimension of the seepage channels in the upper part of the bed is 1.169 , increasing to 1.586 with increasing height. In contrast, the bed volume concentration increases from 0.3 to 0.42 with increasing height. 


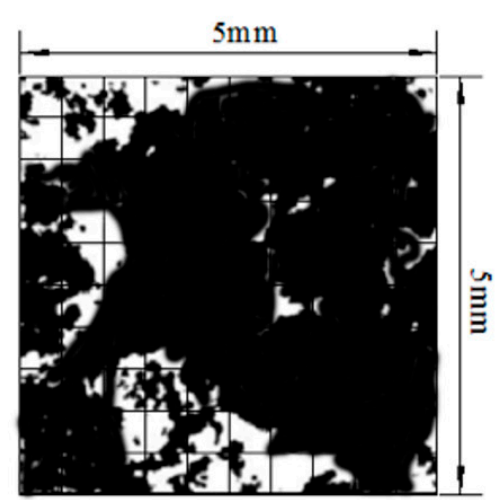

(1) $12 \mathrm{~cm}$

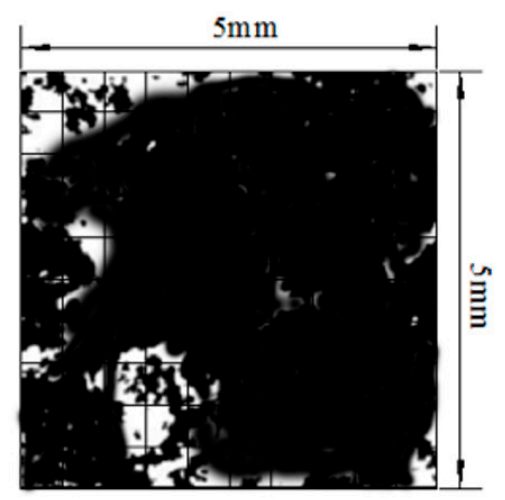

(4) $6 \mathrm{~cm}$

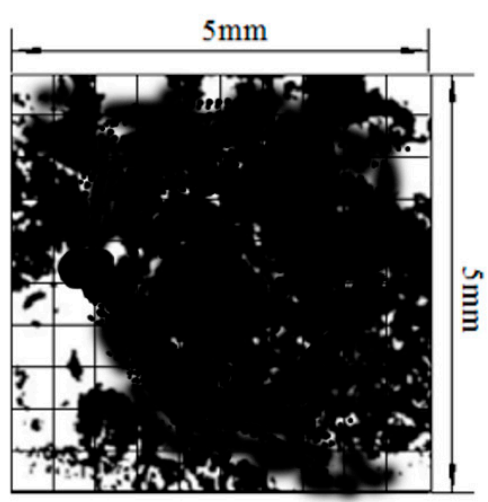

(2) $10 \mathrm{~cm}$

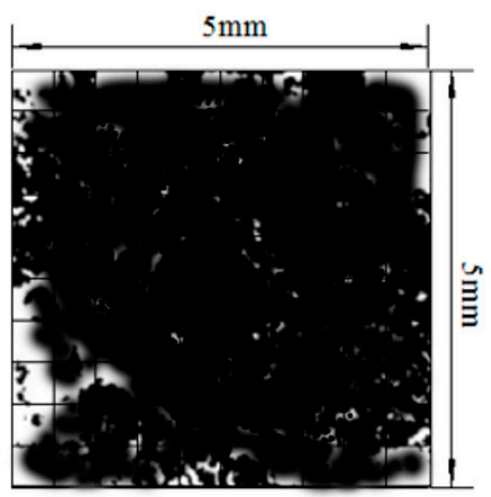

(5) $4 \mathrm{~cm}$

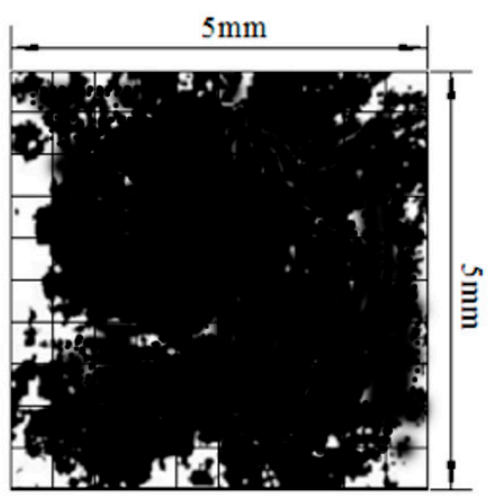

(3) $8 \mathrm{~cm}$

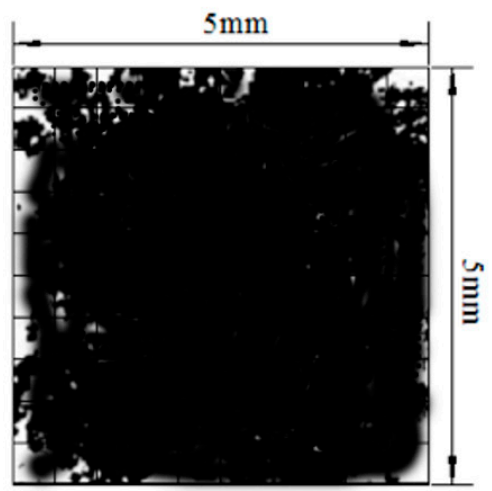

(6) $2 \mathrm{~cm}$

Figure 8. Binarization of the bed seepage channel distribution image under shear and box dimension calculation.

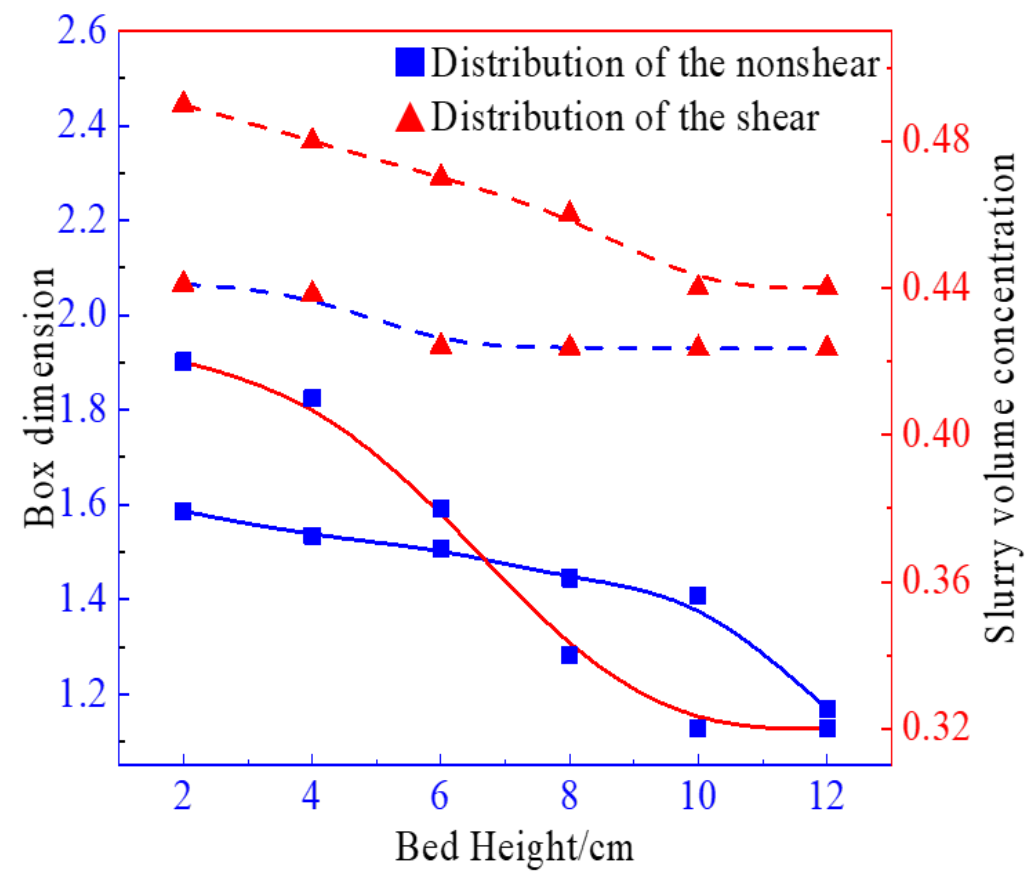

Figure 9. Fractal dimension and internal concentration distribution curves of seepage channels within the bed. 
In the upper part of the bed, the tailings flocs cannot effectively agglomerate and are in a dispersed state. Additionally, the floc structure has high porosity with large floc spacing. Distribution of the shear tailings bed: at the bottom of the bed, the fractal dimension of the flocs reaches the highest value, increasing to 2.08 with increasing height, reflecting the high density of the floc structure and the small spacing, the small porosity of the solids and the large concentration of the slurry. The bed volume concentration increases from 0.44 to 2.42 with increasing height. This phenomenon is because the percolation channels are interconnected, causing the dispersed water between the flocs to gather and breaking the static equilibrium between the flocs and water. Under the action of gravity and lateral pressure of the particles, the water is discharged along the channels, the fractal dimension is further increased, and the flocs tend to be dense.

\subsection{Floc Pore Structure Extraction}

Because the concentration of tailings at the top of the sample is low, the pore structure does not differ substantially and is less effected by shear conditions. Additionally, because the pore structure in the central part of the sample is affected by shear and unstable, a compromise was made by selecting the most stable bottom of the tailings bed for the microscopic study. The pore structure was extracted by selecting cubes of the same volume and size at the same location at the bottom of the bed.

The reconstructed results show that shear causes the pore structure to loosen, and the connected pore structure is divided into several independent pores under shear, increasing the number of pores. After the shearing changes the pore structure, the water is transported to the upper part of the mud layer by the shear force. Some undrained water occurs in the connected pore structure, and some in the second independent pore structure. The space left after the water has been discharged is replaced by tailings particles so that the porosity is enhanced, and the bottom concentration is increased. The pore structure with/without shear action is shown in Figures 10 and 11.
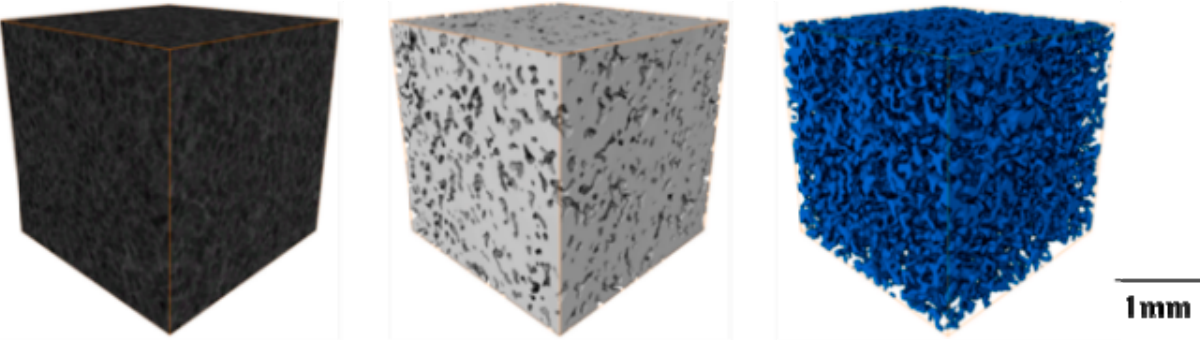

Figure 10. Pore structure under shear.
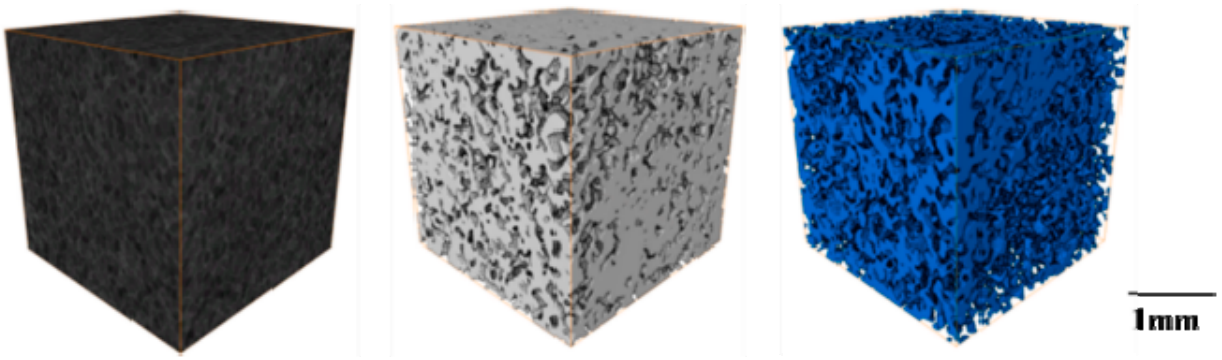

Figure 11. Pore structure in the absence of shear.

\subsection{Pore Structure Extraction of Flocs at Different Heights}

To obtain the bed height direction and the pore distribution pattern before and after shear, $0.5 \mathrm{~mm}$ thick-thin sections were extracted at different heights of the reconstructed model to analyze the fine view pores and plot the porosity curve along the height direction (Figure 12). 


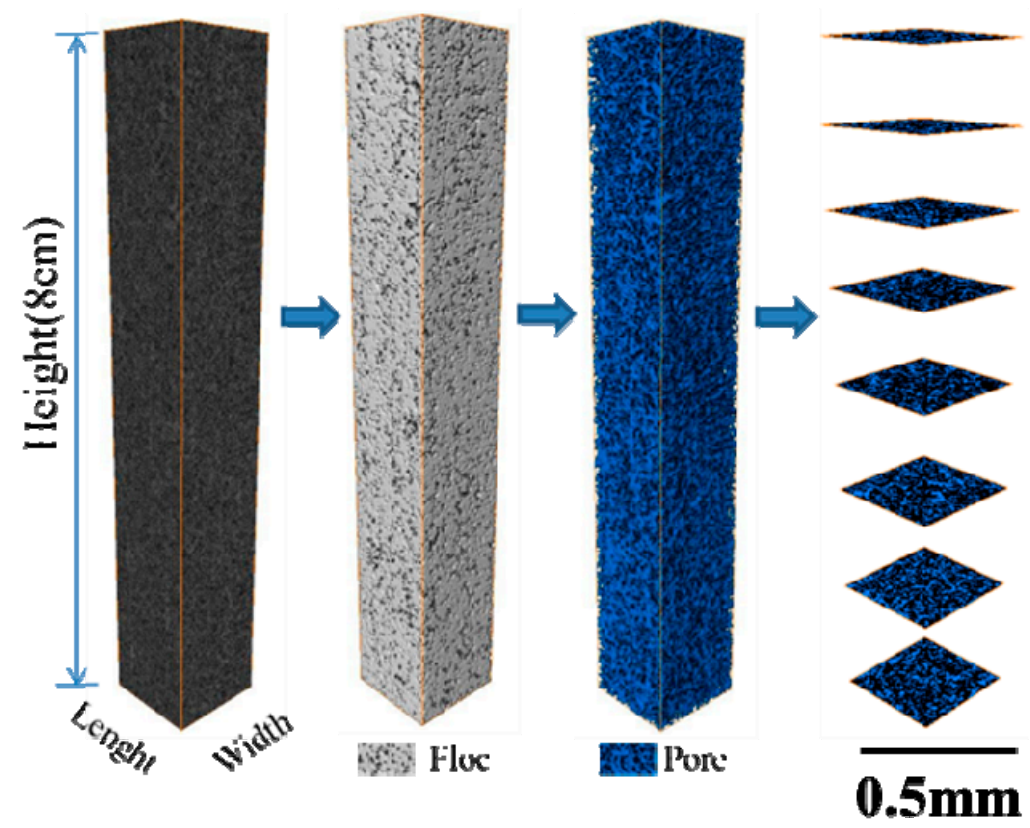

Figure 12. Variation pattern of pore structure extraction versus bed height.

As shown in Figure 13, porosity increases with increasing bed height, with the porosity increasing from $43.4 \%$ to $49.6 \%$ and an average porosity of $47.62 \%$. The average porosity of the specimens with shear slowly increased from $37.8 \%$ to $43.5 \%$, with an average of $40.98 \%$.

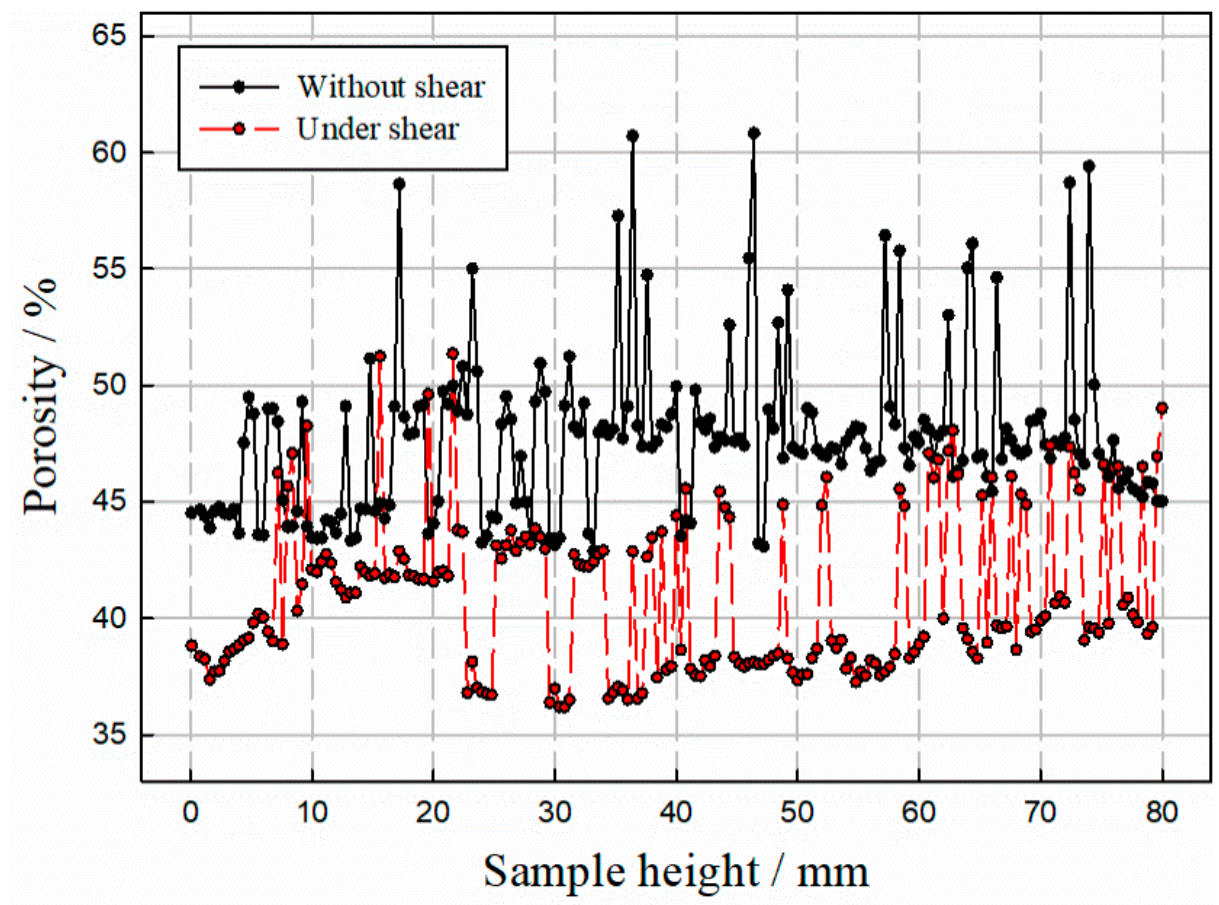

Figure 13. Variation pattern of porosity with sample height under no/with shear conditions.

\subsection{Fine-Scale Characteristics of Pores at Different Heights}

At the bottom of the bed, the compression process is deeper, and the pores are poorly connected in a fragmented manner, exhibiting no connection with the mesh structure in the form of clustered pores. In the middle and upper parts of the bed, the pores are flattened and distributed in a complex shape, with good connectivity between them, and the water can be easily discharged under the guidance of shear. 
The pore structure of the unit was extracted and magnified for observation. The results are shown in Figures 14 and 15. The pore structure under shear was loose, and most of the interconnected pore structures were divided into several independent pore structures under shear, causing an increase in the number of pore structures. The shearing action changes the pore structure. The water is transported from the bottom to the upper part of the mud layer by the shearing action, with some of the undischarged water remaining in the interconnected pore structures and some locked in the individual pore structures. The space previously occupied by the discharged water is replaced by the solid particles of the tailings, resulting in reduced porosity and a higher concentration at the bottom.

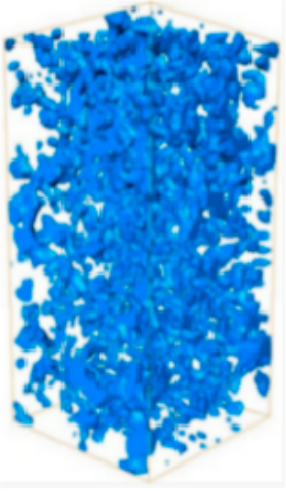

(1)

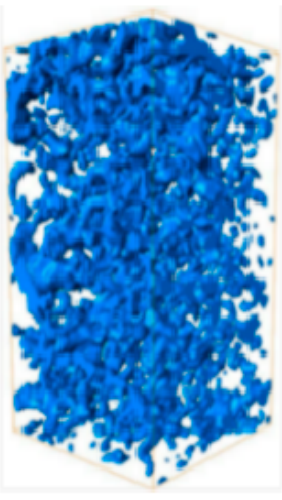

(2)

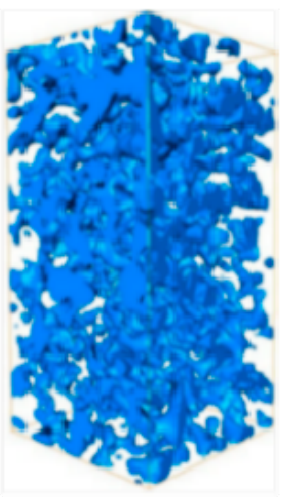

(3)

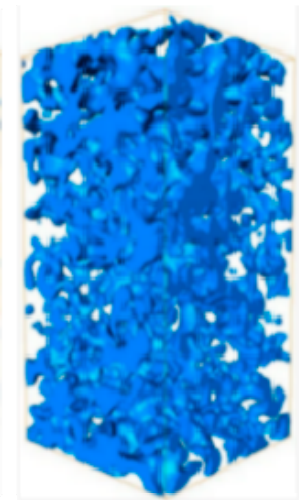

$200 \mu \mathrm{m}$

$(4)$

Figure 14. Fine + view pore structure at different heights within the shear-free sample $(0.5 \mathrm{~mm}$ thick pore distribution). (1) $2 \mathrm{~cm}$ high; (2) $4 \mathrm{~cm}$ high; (3) $6 \mathrm{~cm}$ high; (4) $8 \mathrm{~cm}$ high.

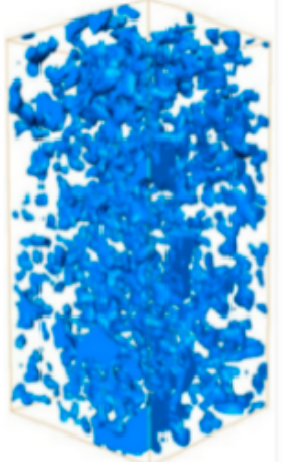

(1)

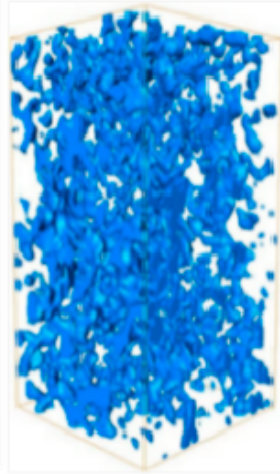

(2)

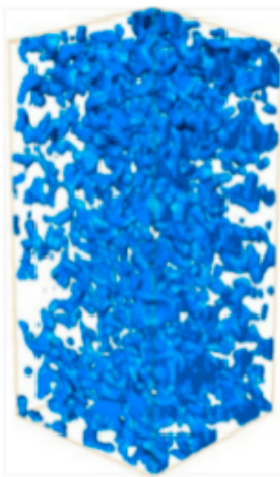

(3)

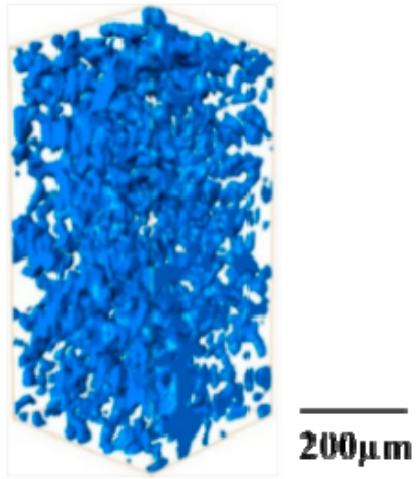

(4)

Figure 15. Fine pore structure at different heights within sheared samples $(0.5 \mathrm{~mm}$ thick pore distribution). (1) $2 \mathrm{~cm}$ high; (2) $4 \mathrm{~cm}$ high; (3) $6 \mathrm{~cm}$ high; (4) $8 \mathrm{~cm}$ high.

Shearing has a small effect on pore morphology but a large effect on the number of pores and the degree of connectivity. The introduction of shear results in a large change in porosity (Figure 15). Therefore, shear action primarily provides the external force required to create seepage channels to expel water.

\section{Discussion}

\subsection{Flocs Stress-Damage—Reverse Seepage}

Simulation of the reconstructed results for percolation in porous media reveals that the pore channels become narrower under shear, which indicates a decrease in flow density. The secondary seepage channels converge to the main seepage channel, forming a well- 
connected main seepage channel in the vertical direction, enhancing the ability to transport water. The water between the pore spaces rises to the upper part of the mud layer along the seepage channel formed by shear. As the shear action proceeds, the water is discharged, and the seepage channel is cut off, leaving part of the water locked in the bed. The concentration of the tailings increases significantly compared with the unsheared state. The discharge of pore water is the most important factor influencing the increase in underflow concentration.

The flow velocity gradient distribution in the pore is shown in Figure 16. The maximum velocity at the pore surface without shear is $9.574 \times 10^{-6} \mathrm{~m} / \mathrm{s}$, and the maximum velocity at the outlet is $5.372 \times 10^{-6} \mathrm{~m} / \mathrm{s}$. The maximum velocity at the pore surface with shear is only $2.499 \times 10^{-6} \mathrm{~m} / \mathrm{s}$, and the maximum velocity at the outlet is $1.468 \times 10^{-6} \mathrm{~m} / \mathrm{s}$. After shear, the sample has poor interpore connectivity, and the liquid is subject to greater viscous resistance when seeping from the bottom upwards. The flow rate is relatively slow due to the large viscous resistance and energy loss when percolating from the bottom upwards.

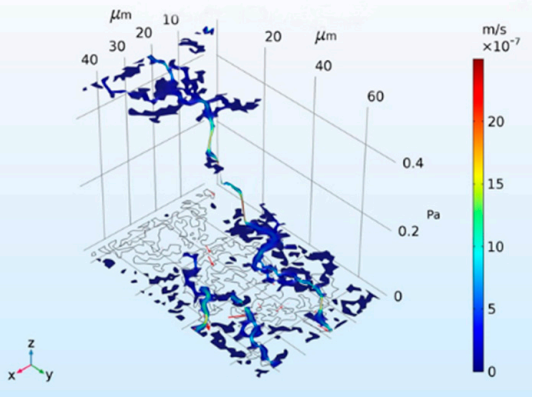

(a)

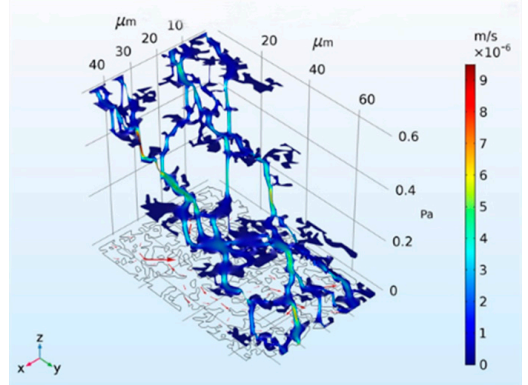

(b)

Figure 16. Comparison of pore surface flow rates (a) with/(b)without shear.

The uneven distribution of solution flow rates is the underlying cause of the uneven pressure distribution, with the highest flow rates often occurring at fine pores with highpressure drops, where the pore disconnects are subject to less pressure and some of the fluid is nearly at rest. At microfissures the seepage velocity is faster, and the pressure is higher, particularly when the fissure channels contract, and the dewatering flow velocity increases abruptly.

The maximum pressure inside the pore space is $484.54 \times 10^{-3} \mathrm{~Pa}$ and $615.76 \times 10^{-3} \mathrm{~Pa}$ with/without shear, respectively, and the fluid flow in the pore space must overcome the resistance along the way, whereby the pressure decreases. The pore pressure is higher because of the greater water content between the pores without shear. The pores are more tortuous and have fewer channels for liquid percolation under shear, resulting in smaller pore pressure due to the effective discharge of water (Figures 17 and 18).

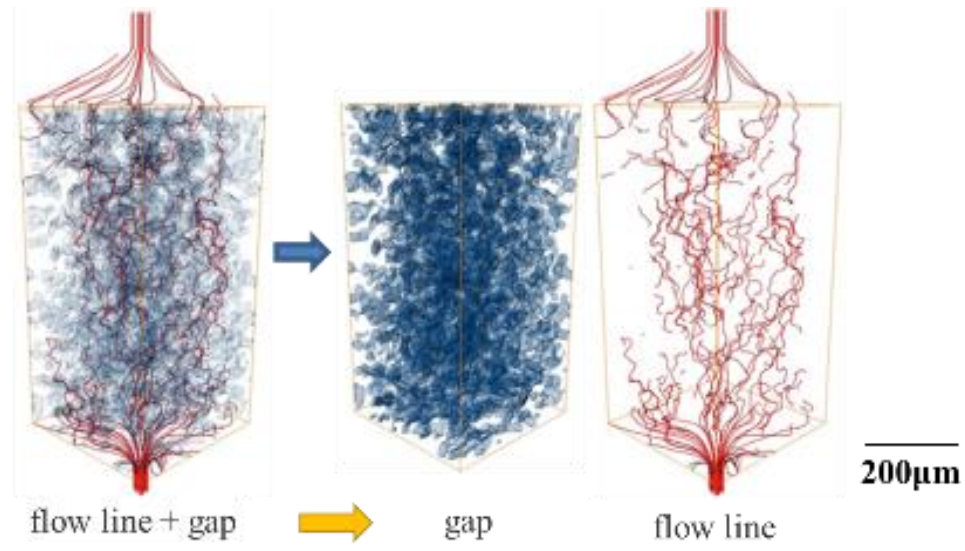

Figure 17. Seepage channel without shear. 


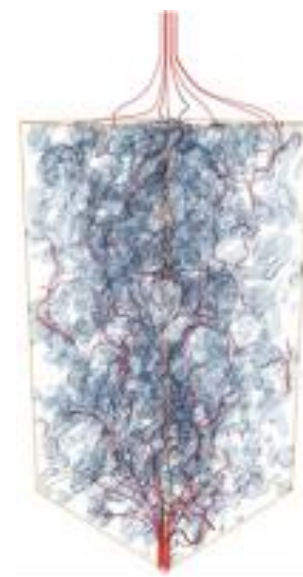

flow line + gap
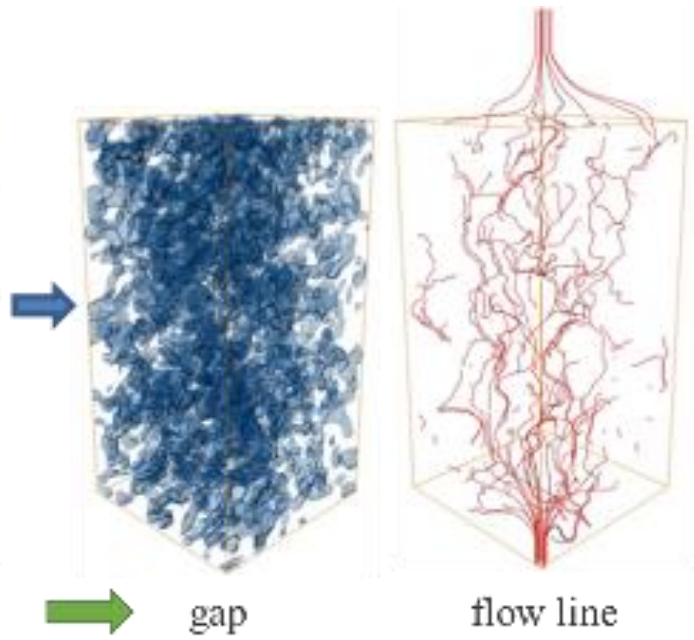

$200 \mu \mathrm{m}$

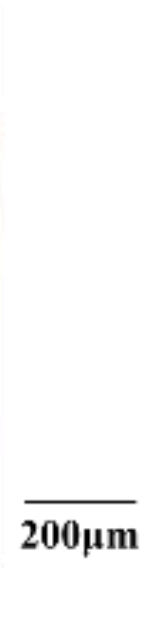

Figure 18. Seepage channel with shear.

\subsection{Mechanisms of Shear Disruption of Floc Densities}

The microscopic distribution of floc percolation channels is shown in Figure 19a,b. In the natural deposition state, the water is uniformly distributed in the lower part of the bed. The flocs are in contact, and the water between and within flocs is stable. The water is not interconnected and eventually forms a static equilibrium with the flocs. The rake shear produces sufficient pressure and tension to break the static equilibrium between flocs and water, causing the water between flocs to be concentrated locally and releasing the water from the flocs by destroying their structure. The stirring action causes the mutual position of the flocs to change continuously, forming the main percolation channel when the upper and lower pores are connected (Figure 19c,d).

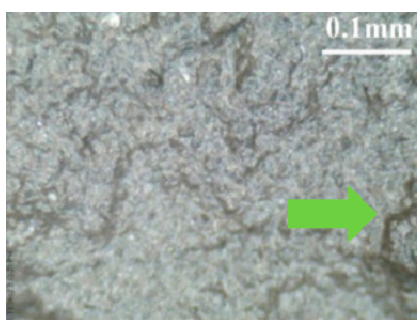

(a)

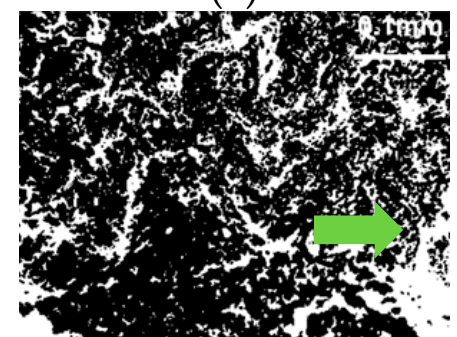

(c)

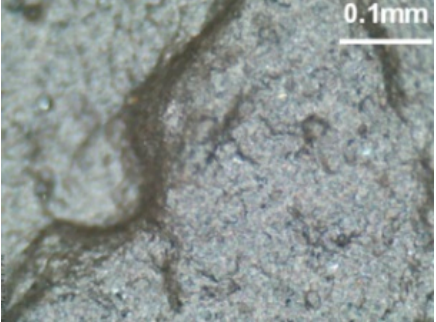

(b)

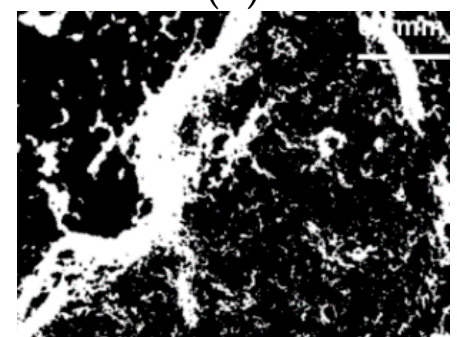

(d)

Figure 19. Effect of agitation on water distribution within the bed. (a) Before mixing (uniform distribution); (b) after mixing (enrichment into main percolation channel). (c) Before microstirring (uniform distribution); (d) after microstirring (enrichment into the main seepage channel).

The force analysis of the flocs and the percolation process are shown in Figures 20 and 21. The addition of agitation causes the originally unconnected water to connect and form a percolation channel. The force imbalance is the driving force for drainage. 


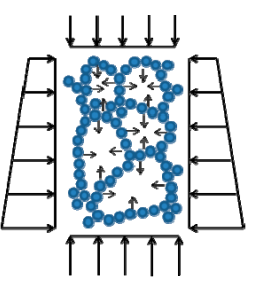

(1)

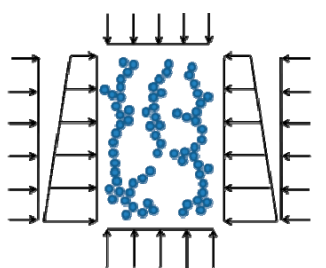

(2)

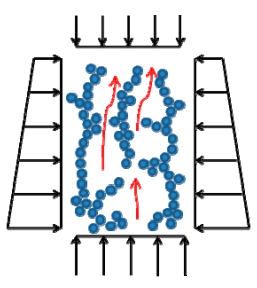

(3)

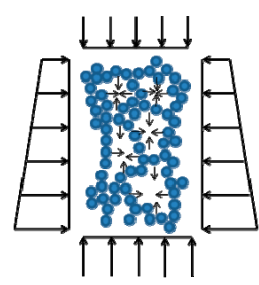

(4)

Figure 20. Lateral compressive stress drainage process. (1) Static equilibrium; (2) disruption of equilibrium by external compressive stress; (3) formation of seepage channels; (4) drainage followed by compaction.

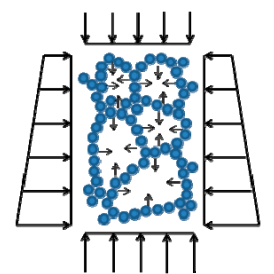

(1)

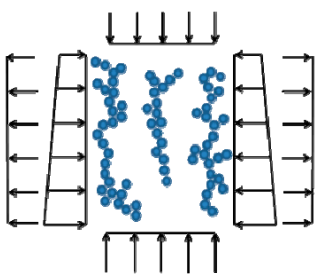

(2)

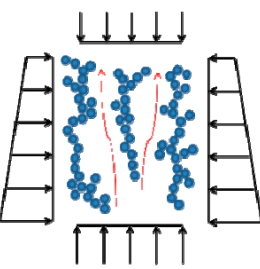

(3)

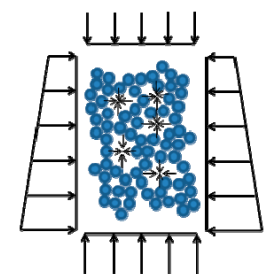

(4)

Figure 21. Lateral tensile stress drainage process. (1) Static equilibrium; (2) disruption of equilibrium by applied tensile stress; (3) formation of seepage channels; (4) drainage followed by compaction.

There are two general types of drainage process: lateral compressive stress drainage and lateral tensile stress drainage. As shown in the diagram, under normal conditions, the internal pressure of the flocs, hydrostatic pressure and gravity form a balance, resulting in a constant relative position of water and flocs within the bed. The mixing process adds lateral compressive and tensile stresses, and the tensile stresses transfer the pressure inside the floc after the floc structure has been destroyed.

The transfer of stress is accompanied by a process of displacement: the seepage channel becomes a stress transfer channel. The hydrostatic pressure and gravity at the lower end of the channel are greater than those at the upper end of the channel, and the water at the lower end is squeezed and discharged upwards. As the lower part of the water is reduced, the original position is occupied by sand particles, the width of the channel is reduced, and the flocs come into contact with one another, thus preventing the already connected seepage channel from forming a new mechanical equilibrium.

The creation and evolution of seepage channels are related not only to externally applied stresses but also to the nature of the strength of the mesh itself (Figure 22). If the mesh itself is strong, it must provide greater external stresses. Highly concentrated solid-liquid mixtures are capable of withstanding not only pressure but also a certain amount of shear.

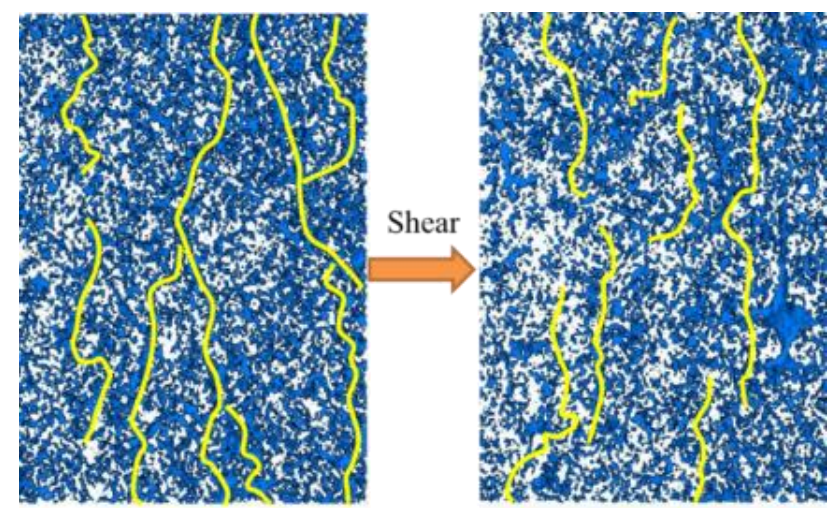

Figure 22. Schematic diagram of the evolution of the seepage channel structure. 


\section{Conclusions}

(1) The distribution of seepage channels can be changed with or without shear, and seepage channels are closely related to the bed height. In the absence of shear, the flocs in the upper part of the bed are widely spaced, and the seepage channels are well developed and obvious.

As the bed height increases, the particles become denser, the number of percolation channels decreases in size, and the bed concentration increases. Under shear action, as shear breaks the static equilibrium between flocs and water, the water is discharged along the channels under the effect of gravity and lateral pressure of the particles, and the partial dimension increases further. However, the overall floc densities were better than those with no shear action.

(2) Shear significantly affects water flow within the pore space. The maximum velocity at the surface of the pore without shear is $9.574 \times 10^{-6} \mathrm{~m} / \mathrm{s}$, and the maximum velocity at the outlet is $5.372 \times 10^{-6} \mathrm{~m} / \mathrm{s}$. The maximum velocity at the surface of the pore with shear is only $2.592 \times 10^{-6} \mathrm{~m} / \mathrm{s}$, and the maximum velocity at the outlet is $1.468 \times 10^{-6} \mathrm{~m} / \mathrm{s}$. After shear, the sample's pores are less well connected, and the liquid is subject to greater viscous resistance when percolating from the bottom upwards. The flow rate was relatively slow due to the large viscous resistance and energy loss when percolating from the bottom upwards.

(3) Shear has a direct effect on the change in pore channels and thus on the distribution of flow lines. The narrowing of the pore channels under shear is reflected in a reduction in flowline density. Shearing causes the secondary seepage channels to converge into the main seepage channel, the flow lines merge, and the ability to transport water increases. The water between the pore spaces rises to the upper part of the mud layer along the seepage channels formed by shearing, which increases the underflow concentration.

(4) Rake shear generates pressure and tension to break the static equilibrium between flocs and water, forming a percolation channel that effectively destroys the floc structure and releases water. The mixing action causes the flocs to change their position with respect to another. When the flocs have reassembled and settled, the concentration of the tailings bed is further increased.

Author Contributions: X.C.: Methodology, Data curation, Writing—original draft. J.Z.: Validation, Formal analysis. H.J.: Conceptualization, Writing-review and editing. K.H.: Supervision. L.W.: Data curation. Z.R.: Writing- Reviewing and Editing. L.Y.: Methodology, Investigation. All authors have read and agreed to the published version of the manuscript.

Funding: This research was funded by [the National Natural Science Foundation of China] grant number (51834001).

Data Availability Statement: Not applicable.

Conflicts of Interest: The authors declare that they have no known competing financial interests or personal relationships that could have appeared to influence the work reported in this paper.

\section{References}

1. Tabelin, C.B.; Park, I.; Phengsaart, T.; Jeon, S.; Villacorte-Tabelin, M.; Alonzo, D.; Yoo, K.; Ito, M.; Hiroyoshi, N. Copper and critical metals production from porphyry ores and E-wastes: A review of resource availability, processing/recycling challenges, socio-environmental aspects, and sustainability issues. Resour. Conserv. Recycl. 2021, 170, 105610. [CrossRef]

2. Tabelin, C.B.; Dallas, J.; Casanova, S.; Pelech, T.; Bournival, G.; Saydam, S.; Canbulat, I. Towards a low-carbon society: A review of lithium resource availability, challenges and innovations in mining, extraction and recycling, and future perspectives. Miner. Eng. 2021, 163, 106743. [CrossRef]

3. Cun, Z.; Fangtian, W.; Qingsheng, B. Underground space utilisation of coalmines in China: A review of underground water reservoir construction. Tunn. Undergr. Space Technol. 2021, 107, 103657.

4. Sahi, A.; El Mahboub, K.; Belem, T.; Maqsoud, A.; Mbonimpa, M. Dewatering of Mine Tailings Slurries Using Superabsorbent Polymers (SAPs) Reclaimed from Industrial Reject of Baby Diapers: A Preliminary Study. Minerals 2019, 9, 785. [CrossRef]

5. Liu, X.; Zhou, F.; Chi, R.; Feng, J.; Ding, Y.; Liu, Q. Preparation of Modified Montmorillonite and Its Application to Rare Earth Adsorption. Minerals 2019, 9, 747. [CrossRef] 
6. Jiao, H.; Chen, W.; Wu, A.; Yu, Y.; Ruan, Z.; Honaker, R.; Chen, X.; Yu, J. Flocculated unclassified tailings settling efficiency improvement by particle collision optimization in the feedwell. Int. J. Miner. Metall. Mater. 2022, 29, 576-587.

7. Su, Z.; Chen, Q.; Zhang, Q.; Zhang, D. Recycling Lead-Zinc Tailings for Cemented Paste Backfill and Stabilisation of Excessive Metal. Minerals 2019, 9, 710. [CrossRef]

8. Jiao, H.; Wu, Y.; Wang, H.; Chen, X.; Li, Z.; Wang, Y.; Zhang, B.; Liu, J. Micro-scale mechanism of sealed water seepage and thickening from tailings bed in rake shearing thickener. Miner. Eng. 2021, 173, 107043. [CrossRef]

9. Jiao, H.; Wang, S.; Yang, Y.; Chen, X. Water recovery improvement by shearing of gravity-thickened tailings for cemented paste backfill. J. Clean. Prod. 2020, 245, 118882.

10. Zheng, D.; Song, W.-D.; Tan, Y.-Y.; Cao, S.; Yang, Z.-L.; Sun, L.-J. Fractal and microscopic quantitative characterization of unclassified tailings flocs. Int. J. Miner. Metall. Mater. 2021, 28, 1429-1439. [CrossRef]

11. Ruan, Z.; Wu, A.; Bürger, R.; Betancourt, F.; Wang, Y.; Wang, Y.; Jiao, H.; Wang, S. Effect of interparticle interactions on the yield stress of thickened flocculated copper mineral tailings slurry. Powder Technol. 2021, 392, 278-285. [CrossRef]

12. Bürger, R.; Diehl, S.; Martí, M.C.; Mulet, P.; Nopens, I.; Torfs, E.; Vanrolleghem, P.A. Numerical solution of a multi-class model for batch settling in water resource recovery facilities. Appl. Math. Model. 2017, 49, 415-436. [CrossRef]

13. Ruan, Z.E.; Li, C.P.; Shi, C. Numerical simulation of flocculation and settling behavior of whole-tailings particles in deep-cone thickener. J. Cent. South Univ. 2016, 23, 740-749. [CrossRef]

14. Chu, H.R.; Wang, Y.H.; Lu, D.F.; Liu, Z.Q.; Zheng, X.Y. Pre-concentration of fine antimony oxide tailings using an agitated reflux classifier. Powder Technol. 2020, 376, 565-572. [CrossRef]

15. Wei, W.; Zhao, Y.; Liu, H.; Song, S. Fabrication and Mechanism of Cement-based Waterproof Material Using Silicate Tailings from Reverse Flotation. Powder Technol. 2017, 315, 422-429.

16. Wilkinson, N.; Metaxas, A.; Quinney, C.; Wickramaratne, S.; Reineke, T.M.; Dutcher, C.S. pH dependence of bentonite aggregate size and morphology on polymer-clay flocculation. Colloids Surf. A Physicochem. Eng. Asp. 2018, 537, 281-286. [CrossRef]

17. Figueiredo, J.; Vila, M.C.; Fiúza, A.; Góis, J.; Futuro, A.; Dinis, M.L.; Martins, D. A Holistic Approach in Re-Mining Old Tailings Deposits for The Supply of Critical Metals: A Portuguese Case. Minerals 2019, 9, 638. [CrossRef]

18. Topaloglu, D.; Tilki, Y.M.; Aksu, S.; Yilmaz, T.N.; Celebi, E.E.; Oncel, S.; Aydiner, C. Novel technological solutions for eco-protective water supply by economical and sustainable seawater desalination. Chem. Eng. Res. Des. 2018, 136, 177-198. [CrossRef]

19. Liu, D.; Edraki, M.; Fawell, P.; Berry, L. Improved water recovery: A review of clay-rich tailings and saline water interactions. Powder Technol. 2020, 364, 604-621. [CrossRef]

20. Sun, Y.; Zhang, X.; Han, Y.; Li, Y. A new approach for recovering iron from iron ore tailings using suspension magnetization roasting: A pilot-scale study. Powder Technol. 2019, 361, 571-580. [CrossRef]

21. Liu, J.; Li, Q.; Li, H. A New Creep Model of Asphalt Mixture Based on Statistical Damage Theory. J. Highw. Transp. Res. Dev. 2014, 31, 13-18. [CrossRef]

22. De Corato, M.; Slot, J.; Hütter, M.; D'Avino, G.; Maffettone, P.; Hulsen, M. Finite element formulation of fluctuating hydrodynamics for fluids filled with rigid particles using boundary fitted meshes. J. Comput. Phys. 2016, 316, 632-651. [CrossRef]

23. Niu, H.; Abdulkareem, M.; Sreenivasan, H.; Kantola, A.M.; Havukainen, J.; Horttanainen, M.; Telkki, V.-V.; Kinnunen, P.; Illikainen, M. Recycling mica and carbonate-rich mine tailings in alkali-activated composites: A synergy with metakaolin-ScienceDirect. Miner. Eng. 2020, 157, 106535. [CrossRef]

24. Liu, L.; Xin, J.; Huan, C.; Qi, C.; Zhou, W.; Song, K.I. Pore and strength characteristics of cemented paste backfill using sulphide tailings: Effect of sulphur content. Constr. Build. Mater. 2020, 237, 117452. [CrossRef]

25. Chuangyun, W.; Mingcang, W.; Di, W. Synthesis of spherical $\mathrm{LiMn}_{2} \mathrm{O}_{4}$ cathode material by dynamic sintering of spray-dried precursors. Powder Technol. 2010, 199, 154-158.

26. Nguyen, C.V.; Nguyen, A.V.; Doi, A.; Dinh, E.; Nguyen, T.V.; Ejtemaei, M.; Osborne, D. Advanced solid-liquid separation for dewatering fine coal tailings by combining chemical reagents and solid bowl centrifugation. Sep. Purif. Technol. 2020, 259, 118172 [CrossRef]

27. Chen, X.; Jin, X.; Jiao, H.; Yang, Y.; Liu, J. Pore Connectivity and Dewatering Mechanism of Tailings Bed in Raking Deep-Cone Thickener Process. Minerals 2020, 10, 375. [CrossRef]

28. Mashifana, T.; Sithole, T. Clean production of sustainable backfill material from waste gold tailings and slag. J. Clean. Prod. 2021, 308, 127357. [CrossRef]

29. D'Avino, G.; Hulsen, M.A. A comparison between a collocation and weak implementation of the rigid-body motion constraint on a particle surface. Int. J. Numer. Methods Fluids 2010, 64, 1014-1040. [CrossRef]

30. Jiao, H.Z.; Wang, S.F.; Wu, A.X.; Shen, H.M.; Wang, J.D. Cementitious property of $\mathrm{NaAlO}_{2}$-activated Ge slag as cement supplement. Int. J. Miner. Metall. Mater. 2019, 26, 112-121. [CrossRef]

31. Ejtemaei, M.; Ramli, S.; Osborne, D.; Nguyen, A.V. Synergistic effects of surfactant-flocculant mixtures on ultrafine coal dewatering and their linkage with interfacial chemistry. J. Clean. Prod. 2019, 232, 953-965. [CrossRef]

32. Wang, D.L.; Zhang, Q.L.; Chen, Q.S.; Qi, C.C.; Feng, Y.; Xiao, C.C. Temperature variation characteristics in flocculation settlement of tailings and its mechanism. Int. J. Miner. Metall. Mater. 2020, 27, 1438-1448. [CrossRef]

33. Jiao, H.; Wu, Y.; Wang, W.; Chen, X.; Wang, Y.; Liu, J.; Feng, W. The Micro-Scale Mechanism of Metal Mine Tailings Thickening Concentration Improved by Shearing in Gravity Thickener. J. Renew. Mater. 2021, 9, 637-650. [CrossRef] 
34. Gao, W.; Wang, H.; Chen, H.; Yang, L.H.; Zhang, L. Study on Main Factors of Underflow Concentration in the Dynamics Thickening Process of Tailings. Met. Mine 2016, 45, 102.

35. Tian, M.; Bi, W.; Row, K.H. Simultaneous Extraction and Separation of Flavonols and Flavones from Chamaecyparis obtusa by Multi-phase Extraction using an Ionic Liquid-modified Microsphere Polymer. Phytochem. Anal. 2012, 23, 576-581. [CrossRef]

36. Zhang, B.; He, Q.; Lin, Z.; Li, Z. Experimental study on the flow behaviour of water-sand mixtures in fractured rock specimens. Int. J. Min. Sci. Technol. 2020, 31, 377-385. [CrossRef]

37. Tang, P.; Jiang, W.; Lyu, S.; Wu, Y.; Qiu, Z.; Sui, Q. Application of glutamate to enhance carbon tetrachloride (CT) degradation by $\mathrm{Fe}(\mathrm{II})$ activated calcium peroxide in the presence of methanol: CT removal performance and mechanism. Sep. Purif. Technol. 2020, 236, 116259. [CrossRef]

38. Chen, F.; Xu, B.; Jiao, H.; Chen, X.; Shi, Y.; Wang, J.; Li, Z. Triaxial mechanical properties and microstructure visualization of BFRC. Constr. Build. Mater. 2021, 278, 122275. [CrossRef] 